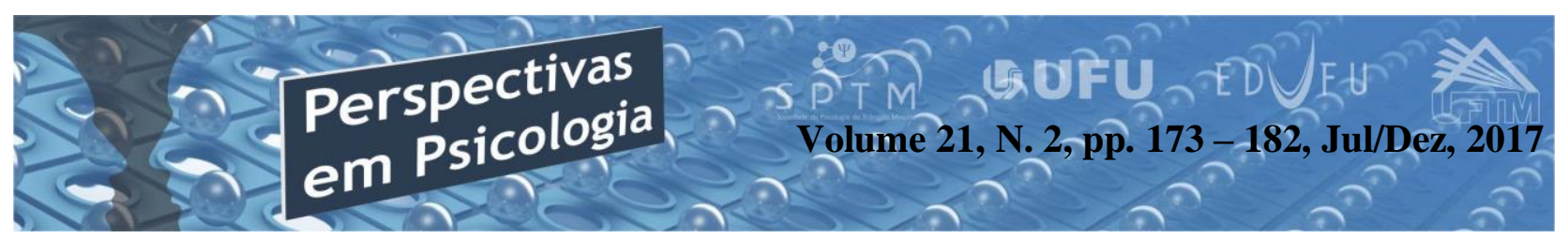

\title{
A DIFERENÇA DOS SEXOS: LACAN E O FEMINISMO
}

\author{
Rafael Kalaf Cossi \\ (Universidade de São Paulo - USP, São Paulo - SP)
}

\begin{abstract}
Resumo
Esta comunicação de defesa de doutorado aborda a interface entre a psicanálise lacaniana e o universo feminista concernente à diferença dos sexos. Examinamos obras de autoras do feminismo psicanalítico francês e dos gender studies. Verificamos o impacto da obra de Stoller para o estabelecimento da noção lacaniana de semblante. Detectamos que noções correlatas ao registro simbólico lacaniano foram criticadas em solo norte-americano e francês. Sustentamos que as inovações propostas pela teoria da sexuação lacaniana, as decorrências de seus aforismos e seu esforço de formalização revigoram a concepção da diferença dos sexos, desviando-a das prescrições binárias dos gêneros.
\end{abstract}

Palavras-chave: diferença dos sexos; psicanálise; feminismo; gênero; sexuação.

\section{Abstract \\ The difference between the sexes: Lacan and feminism}

This PHD defense communication addresses the interface established between lacanian psychoanalysis and the feminist field concerning the difference between the sexes. We examined french psychoanalytic feminism's and gender studies's works. We verified the impact of Stoller's work on the Lacanian notion of semblant. We have detected that notions related to the lacanian symbolic register are criticized in both North American and French territories. We argued that the innovations proposed by the lacaninan theory of sexuation, the consequences of its aphorisms and its efforts to formalize them reinvigorate the conception of the difference between the sexes, escaping from the gender binary prescriptions.

Keywords: difference between the sexes; psychoanalysis; feminism; gender; sexuation.

$\mathrm{O}$ tema de nossa pesquisa de doutorado é a diferença dos sexos em psicanálise lacaniana, notadamente em debate com o meio feminista, que se deu no Instituto de Psicologia da Universidade de São Pulo sob orientação do professor titular Christian Dunker. O interesse por esse assunto decorre do nosso trabalho de mestrado, dedicado à leitura psicanalítica da transexualidade, quadro clínico que escancara a não 
correspondência entre sexo e gênero. Lá defendemos que reduzir toda experiência transexual a uma estrutura clínica é um erro crasso, e nos colocamos contra toda uma tradição consolidada dentro do lacanismo. Tal vertente parte da premissa de que a travessia do percurso edípico - a partir do que o menino se identifica com o masculino e a menina com o feminino - prescreve um ideal de normalidade neurótico e heterocêntrico. E como seriam encarados os casos da incongruência entre o aparato anatômico do sexo do indivíduo e a identificação sexual assumida? Tratar-se-ia de psicose, por exemplo? A filósofa Judith Butler ilumina um problema sério a respeito de conduta clínica desta parcela da psicanálise: retroativamente, ter adotado a coerência entre sexo e gênero como critério diagnóstico. E mais, que a psicanálise teria se restrito a um dualismo de gêneros - os gêneros ininteligíveis, fora da díade masculino-feminino, seriam inconcebíveis e patologizáveis.

Provém do entusiasmo com a astúcia butleriana nosso primeiro projeto de doutorado: "A problemática da diferença sexual: entre Butler e Lacan”. Nós já tínhamos verificado o quanto as críticas butlerianas eram úteis, mas partimos da hipótese de que ela talvez não tivesse contemplado a sexuação lacaniana - essa teoria, ao enfatizar a noção de gozo e o registro do real, traria um frescor para a polêmica travada entre Lacan e os estudos de gênero, indo além dos fatores sexo biológico, gênero, desejo e práticas sexuais já contemplados pela filósofa. Após nos aprofundarmos nos trabalhos dela que dialogavam com Lacan, verificamos uma repetição: seu principal ponto de crítica ao lacanismo concernia ao registro simbólico e noções correlatas, como lei simbólica, pai simbólico, falo simbólico - o simbólico formataria a diferença sexual em termos binários, homem/mulher, deliberando a heterossexualidade como norma; seria uma espécie de mantenedor da relação de parentesco ditada pelo patriarcado. Ademais, teríamos um registro ahistórico avesso a mudanças. Verificamos na sequência que autores como Zizek (in Barnard \& Fink, 2002), Zupancic (2012), Copjec (1994), Ragland-Sullivan (2004) escrevem textos criticando esta leitura butleriana do simbólico, apontado que a filósofa teria negligenciado a dimensão real da diferença sexual, as modalidades de gozo, que implementam a contingência no terreno do sexo.

Feita esta primeira pesquisa, resolvemos então expandir nosso leque e abordarmos as feministas que se voltaram a 
Lacan, que inclusive foram lidas e comentadas por Butler. Fomos descobrindo autoras e chegamos a nomes como Luce Irigaray, Monique Wittig e Gayle Rubin, Beatriz Preciado além de Hèléne Cixous e Michèle Montrelay. E, em outro contexto, a Robert Stoller.

A nossa tese foi dividida em três grandes capítulos: Lacan e o feminismo francês, com subitens dedicados a Irigaray, Cixous, Montrelay, Kristeva e Wittig; Lacan e os estudos de gênero de inspiração norteamericana - aqui são privilegiados os trabalhos de Rubin e Butler. Nesta parte, também incluíamos Preciado, que quer fazer avançar a concepção de gênero enquanto performance através da tecnologia, e a obra de Stoller, psiquiatra e psicanalista norteamericano, que trouxe a noção de gênero para dentro da psicanálise nos anos 60 . O terceiro capítulo expõe nossa interpretação da teoria da sexuação lacaniana.

O feminismo francês foi fortemente influenciado pela noção de falogocentrimo de Derrida. Sistemas falogocêntricos se apoiam numa lógica da identidade fundada na polarização binária da diferença, oposição que leva à hierarquia entre seus termos, à submissão de um pelo outro. Essa forma de pensamento estaria na base do patriarcado e da psicanálise, no interior da qual o homem teria sido identificado com o significante fálico e à mulher qualquer protagonismo ontológico teria sido barrado. Para desmantelar este quadro, recorre-se ao modelo da desconstrução, que fornece técnicas de desestruturar textos, e à proposta de differenace, visando desarticular aquele esquema binário da diferença que acabou servindo como base para o entendimento da diferença sexual.

A filósofa e psicanalista Luce Irigaray colaborou com seminários XII e XIV de Lacan, mas com a publicação de seu primeiro livro, Speculum de l'atre femme, de 1974, foi expulsa de sua escola. Grosso modo, para ela, o lacanismo, apoiado em instrumentos teóricos mais refinados do que Freud tinha a sua disposição, como a linguística de Saussure e o estruturalismo de Levis-Strauss, apresentava uma versão renovada do impedimento da mulher a aceder ao campo discursivo em seus próprios termos. Além de lutar por direitos, não há, para Irigaray, como promover mudanças neste cenário sem intervir na linguagem: propõe-se então a invenção de um tipo de escrita revolucionária cujo funcionamento, se transposto ao nível das relações sociais, traria novidades: nasce então o "movimento da escrita feminina", tendo Hèlénè Cixous como seu grande entusiasta - inclusive um trabalho desta 
autora é comentado e elogiado por Lacan no seminário XXIII, a peça de teatro "Retrato de Dora”.

Cixous considera Clarice Lispector como uma legítima representante deste tipo de escrita que pretendia inscrever o gozo feminino, imprevisível e incontrolável, o que seria o mais próprio da mulher, em texto. Neste sentido, há de se romper com regras gramáticas, subverter a sintaxe, forjar novas palavras, como forma de desmantelar a linguagem para talvez até se conceber uma outra, que pudesse se sustentar em alicerces não fálicos, para além da fixidez do simbólico e das relações de poder masculinas instituídas por ele, na ótica de Cixous (1975/1981). Já Michele Montrelay foi quem apresentou a Lacan o trabalho de Marguerite Duras, "O arrebatamento de Lol von Stein”. Montrelay (1977) elabora a noção de sombra abrilhantando o gozo feminino e trata metapsicologicamente da escrita do corpo da mulher - a personagem Lol seria seu emblema, embebida numa experiência gozosa que flertava com o vazio e a desmesura, sem que tal expediente fosse patologizado. Montrelay discorre sobre a técnica psicanalítica a ser renovada pelo feminino - a escrita do gozo poderia ser de certa forma trespassada para trabalho psicanalítico, engrandecendo seus recursos ao ultrapassar o enfoque no significante. Júlia Kristeva também pensa num tipo de texto capaz de promover transformações sociais, mas a partir de outro arcabouço teórico - ela inventa a "semanálise": semântica junto à psicanálise. A idéia é acionar o que denominou como período semiótico, estágio anterior à entrada do sujeito no simbólico - se o simbólico implementa a ordem, prescreve leis e fixa identidades, segundo Kristeva (1974/1984), o semiótico é disruptivo e regido por pulsões em estado disperso conjectura-se dirigir este mecanismo para a maneira com que se escreve textos, privilegiando a musicalidade, o ritmo e o nonsense. Estamos na fase pré-edípica, na qual a diferença sexual ainda não foi implantada - dai a autora rejeitar o nome escrita "feminina". Cabe apontar que Lacan também estava atento a Kristeva: no seminário XIV, ele se diz muito interessado num trabalho dela chamado Polylogue. Também é digno de nota o caso em que Lacan ia compor, junto dela, Barthes e outros, aquela famosa expedição à China: Lacan queria explorar o inconsciente chinês, que segundo Kristeva seria estruturado como uma escrita. Monique Wittig endossa aquele tipo escrita como motor de novidades e também discorda do termo feminino a compor "escrita feminina", mas tendo em vista algo diferente. 
Ela quer derrocar a heterossexualidade enquanto regime político. Se o patriarcalismo só se sustenta na submissão da mulher, temos de abolir mulher e homem enquanto categorias para assim minar o sistema. Os elementos sexo e gênero também devem ser destruídos - afinal de contas, gênero sempre acaba remetendo, para Wittig (1992), a sexo masculino e feminino, ou seja, a termos que só existem dentro do cenário heterossexual. E se a psicanálise lacaniana também concebe a diferença sexual nesses moldes, ela também deve desmoronar. Wittig (1992) critica o esvaziamento de conteúdo de noções como a de simbólico, tido como um registro transcendental, negativizado e distante do mundo prático, o que seria no fundo uma tática para manter a ordem e o poder tal como se apresentam: em conclusão, não haveria como combater o que não tem realidade social, segundo a autora.

Verificamos, portanto, que o grande problema é o simbólico, tanto para as feministas francesas quanto para os estudos de gênero norte-americanos. Mas nos EUA a porta de entrada foi outra. Se o feminismo francês se verteu ao Lacan dedicado à ciência da linguagem, os estudos de gênero se focaram naquele que se sustentou nos trabalhos de Levi-Strauss a respeito das estruturas elementares de parentesco. Rubin foi quem em 1975 concebeu o famoso sistema sexo/gênero, fundando toda uma linha de pesquisa. Para ela, o simbólico lacaniano e a circulação do falo subsidiariam as relações sociais que condenam as mulheres a serem objetos de troca. A castração é encarada como dimensão subjetiva da proibição estruturante da ordem social, o tabu do incesto. A lei simbólica põe limites ao social - se valida certos arranjos, bane as práticas amorosas não- heterossexuais. Temos um Lacan atrelado à ideologia dominante, então. Butler (1993/2003) problematiza dois aspectos que consideramos fundamentais: o atrelamento de ser o falo à mulher e ter o falo, ao homem, além da obscura tese de Lacan, presente em “A significação do falo" (1958/1998), de que a castração tem como função permitir que o sujeito assuma o tipo ideal do seu sexo. Por outro lado, Schepherdson (2000) questiona a leitura feminista do simbólico: para ele, confundiu-se lei simbólica com norma; também teria sido um engano tomar o simbólico como ahistórico. Se a sexualidade humana tem uma história, ou seja, se existem diversas manifestações da sexualidade para além da meta da reprodução sexual, é porque o sujeito é marcado pelo simbólico. O simbólico não dita esta ou aquela relação de parentesco como ideal a ser atingido, mas permite justamente que a variedade seja 
possível; não cria as relações de poder ou o binarismo dos gêneros, mas fornece os meios para que quaisquer relações possam ser tecidas - o simbólico teria sido equivocadamente "sociologizado". Outra reação notável foi a de Leguil (2015) e Copjec (1994): é como se elas considerassem que o exame feito pelos estudos de gênero distorcesse fundamentos da teoria psicanalítica - noções como desejo, falo e sexo deveriam ser retratadas, então. Talvez não à toa toda esta querela tenha ganhado profusão: simbólico, falo, sexo em psicanálise são pontos cegos da teoria. Nesse sentido, Butler, Preciado e as feministas francesas prestam um profundo serviço à psicanálise: elas nos obrigam a falar sobre os nossos obtusos pilares teóricos, esquivos, e a nos reposicionar politicamente, dentro e fora do consultório e de nossas instituições de transmissão.

Mas toda essa discussão sobre gênero teve origem em outro campo, no caso, em âmbito médico, com Robert Stoller e o John Money nos anos 60. Como o termo sex em inglês faz alusão direta a sexo biológico, fezse necessário requisitar outro a privilegiar o que é socialmente construído, opondo-se radicalmente à materialidade do corpo - dai a importação da palavra gender, elemento ontologizado a compor a identidade sexual.
Se no seminário XX Lacan se mostrava atento ao "Movimento de liberação das mulheres", já no seminário XVIII, ele discute o transexual de Stoller e logo em seguida, ao criticar as precondições stollerianas da identidade de gênero, apresenta um ponto de virada nas suas composições teóricas. Stoller perseguia ao longo de toda sua obra algo o que ele intitulou de "núcleo de identidade de gênero" (Stoller, 1968/1984), que seria responsável pela conviç̧ão do sujeito de que se é homem ou mulher, crer-se como um ou outro, independentemente do corpo anatômico, dos seus comportamentos e de suas práticas sexuais. A nosso ver, Lacan toma essa noção de Stoller como contraponto para o desenvolvimento de sua teoria dos semblantes, e afirma que não existe o quê permita ao sujeito se afirmar, por si só, como homem ou mulher, mas que o outro precisa entrar em jogo: o menino faz semblante de homem para a menina, que o reconhece como tal, e vice-versa, o que toma como condição a consolidação de uma certa relação entre os sexos. Só há semblante, já que não há representação de homem e mulher no inconsciente. Então, neste seminário XVIII, Lacan dá um salto: saímos da teoria dos discursos (semblante é um lugar do discurso) para a teoria da sexuação; o semblante é 
sexualizado. E logo em seguida, outro avanço: Lacan decreta a não relação sexual.

A partir dos anos 70, algumas novidades se dão na esfera da teoria lacaniana: o falo é alçado ao status de função dentro da lógica - função fálica - assim como passa a adjetivar um tipo de gozo, o gozo fálico; o mito de totem e tabu é vigorosamente retomado; a noção de gozo ganha mais espaço quando se trata da diferença dos sexos; o registro do real ganha destaque especial; Lacan declara os aforismos "A mulher não existe" e "A relação sexual não existe" e "Hádo-Um", a serem formalizados a partir de recursos da escrita lógica, da teoria dos conjuntos e dos números - de Parmênides a Frege, Lacan se esforça bravamente para falar de homem e mulher a partir do zero e do um, ou seja, não se trata de um mais um que leva a dois, duas substâncias ou entidades, tal como prevê as dicotomias ou relações binárias. Não há duas essências ou dois universais - se houvesse, poderíamos pensar em maneiras de se relacionarem, heterossexualmente ou por oposição hierárquica, por exemplo. Para Lacan, "a relação sexual não existe": há um todo e um não-todo, um só universal e dois regimentos fálicos heterogêneos, assim como são os dois tipos de existência. A relação do lado homem se dá com objeto $a$ e, do lado mulher, com o falo e o $\mathrm{S}(\mathbb{A})$, o que leva ao desígnio de duas modalidades de gozo incompatíveis e não complementares. Por sinal, a constatação do desencontro e da discrepância entre homem e mulher aparece em Lacan desde o início de seu ensino, ao discorrer sobre a falta, o desejo e a fantasia, o que serve de prévia à sua "não relação sexual", agora categoricamente enunciada no seminário XVIII.

Daí nossa tese principal: estamos nos anos 70, o feminismo francês está em ebulição, e como Lacan prodece? Não verificamos 0 psicanalista rebater diretamente em seus ditos e escritos as críticas a ele endereçadas por Irigaray e Cixous, dentre outras. Mas sim decretar a não relação sexual e se dedicar com afinco à sua formalização. Não é que Lacan negue que a diferença sexual também pertence ao espaço biológico ou do gênero, mas, insiste que é com a formalização da não relação sexual que o discurso psicanalítico pode originalmente contribuir para este tema (Lacan, 197273/2010).

Nesta perspectiva, qual seria a forma com que Lacan se debruça sobre a diferença sexual?

$\mathrm{Na}$ filosofia clássica, a diferença sexual não tem estatuto ontológico, ela não é um filosofema, de acordo com Fraisse (2010). Homens e mulheres eram sempre abordados 
a partir de um terceiro elemento, como o amor, o pensamento ou o corpo - importava como homens e mulheres lidavam com eles. Lacan também: ele fala em função fálica e gozo, ou seja, Lacan também não trata do que seria a diferença sexual em si. A teoria da sexuação não é uma teoria essencialista que visa definir o que homens e mulher são, não só a partir de corpo sexuado, gênero ou práticas sexuais -, mas também com relação ao gozo - não se pode dizer que homens são aqueles que gozam falicamente e mulheres são aquelas que acessam o gozo Outro. Lacan não se dedica então à diferença concebida a partir de dois elementos diferentes a serem contrapostos, como dois corpos distintos ou duas identidades antagônicas, nem a uma diferença vertical, um único elemento tomado em graus diferentes, tal como a pesquisa de Laqueur (2001) revela sobre o entendimento da diferença sexual na época do Renascimento: o que diferenciava homem e mulher era a quantidade de calor, prevalecendo o modelo isomórfico dos copos. Com Lacan, nem absoluto nem relativo, leitura esta também sustentada por Le Gaufey (2007). O que lhe interessa é a relação e o impasse que ela comporta. $\mathrm{O}$ termo "diferença dos sexos", segundo Fraisse (2010), aponta para o reconhecimento de um conflito inerente à relação entre os sexos, um desacordo, antiga concepção da diferença dos sexos que Lacan resgata.

A relação sexual falha e falha de duas maneiras assimétricas. Como tal, ela não pode ser escrita, mas e a não-relação? Lacan busca uma maneira de escrever o que faz obstáculo entre os lados das fórmulas da sexuação - dai as subversões lacanianas à lógica aristotélica e a invenção de sua lógica do não-todo.

Por fim, o ponto espinhoso é se a sexuação poderia contribuir para os estudos de gênero. Braidotti (in Brennan, 1997) diz que a teoria psicanalítica é interessante, mas não enxerga nela potencial para mudanças sociais concretas. Fink (1998) e RaglandSullivan (2004) pensam que se trata de métodos e propostas distintos e incomunicáveis. Nesse ponto, nos colocamos ao lado de Saez (2004) e Cornell (in Benhabib,1995): se a desintegração das identidades é uma meta feminista almejada, o aforismo "A mulher não existe" o contempla em larga escala. Se se pretende uma alternativa ao binarismo de gênero, a "não relação sexual" tem um potencial enorme ainda a ser explorado. 


\section{Referências}

Barnard, S.; Fink, B. [Org.] (2002). Reading seminar XX: Lacan's major work on love, knowledge and feminine sexuality. EUA, State University of New York Press.

Benhabib, S [et.al] (1995). Feminist contentions: a philosophical exchange. New York/London, Routledge.

Brennan, T. [Org.] (1997). Para além do falo: uma crítica a Lacan do ponto de vista da mulher. Rio de Janeiro, Record / Rosa dos tempos

Butler, J. (2010) Cuerpos que importan. Sobre los límites materiales y discursivos del «sexo». Buenos Aires, Paidós (original publicado em 1993).

Cixous, H. (1981) The laught of the Medusa. In: Marks, E.; De Courtivron, I. New french feminism. USA, Schocken Books, (original publicado em 1975).

Copjec, J. (1994) Read my desire-Lacan against the historicists. Cambridge MA/ Londres, MIT Press.

Fink, B. (1998) O sujeito lacaniano: entre a linguagem e o gozo. Rio de Janeiro, Jorge Zahar Ed.

Fraisse, G. (2010). À côté du genre : sexe et philosophie de l'égalité. Lormont, Le bord de l'eau.

Irigaray, L. (1974) Speculum: de l'autre femme. Paris, Les éditions de Minuit.

Kristeva, J. (1984) Revolution in poetic language. Nova York, Columbia Press Univesity. (original publicado em 1974).

Lacan, J. (1958/1998) A significação do falo. In: Os escritos. Rio de Janeiro, Jorge Zahar.

Lacan, J. (1971/2009) O seminário, livro 18 - de um discurso que não fosse semblante. Rio de Janeiro, Jorge Zahar Ed.

Lacan, J. (1972-73/2010) Encore. Versão Escola da letra freudiana. Rio de Janeiro.

Lacan, J. (1975-76/2007) O seminário, livro 23 - o sinthoma. Rio de Janeiro, Jorge Zahar Ed.

Lacan, J. (1976-77) Le séminaire, livre XXIV-L'insu que sait de l'une-bévue s'aile à mourre [Versão Stafela].

Laqueur, T. W. (2001) Inventando o sexo: corpo e gênero dos gregos a Freud. Rio de Janeiro, Relume Dumará.

Le Gaufey, G. (2007) El notodo de Lacan: consistencia lógica, consecuencias clínicas. Buenos Aires, El cuenco de plata. 
Leguil, C. (2015). L'être et le genre - hommelfemme après Lacan. Paris, Presses Universitaires de France.

Rubin, G. (1975) The traffic in women: notes on the "political economy" of sex. Recuperado em: <https://genderstudiesgroupdu.files.wordpress.com/2014/08/therraffic-in-women.pdf $>$.

Saez, J. (2004). Teoría queer y psicoanalisis. Madrid, Editorial Sintesis.

Shepherdson, C. (2000) Vital signs: nature, culture, psychoanalysis. Nova York, Routledge.

Stoller, R. J. (1984) Sex and gender: the development of masculinity and feminility. Londres, Karnac Bookks. (original publicado em 1968).

Ragland-Sullivan, E. (2004) The logic of sexuation: from Aristotle to Lacan. Albany, Sunny University of New York Press.

Wittig, M. (1992) The straight mind and other essays. Boston, Beacon Press books.

Zupančič, A. (2012). Sexual difference and ontology, E-flux journal \# 32.

\section{O Autor:}

Rafael Kalaf Cossi possui graduação em Psicologia pela Universidade de São Paulo (2000), títulos de especialista pelo curso Teorias, técnicas e estratégias especiais em psicanálise, Instituto de PsicologiaUSP (2002), de mestre (2010) e doutor (2017) pelo Departamento de Psicologia Clínica - USP. É membro do grupo de pesquisa sobre o corpo do Laboratório de Teoria Social, Filosofia e Psicanálise (LATESFIP-USP) e participante das atividades da Escola de psicanálise do fórum do campo lacaniano (EPFCL-SP). E-mail: rkcossi@ hotmail.com

Recebido em: 07/07/2017

Aprovado em: 29/07/2017 